\title{
La educación democrática en el contexto de la deliberación y el agonismo político*
}

\author{
Political philosophy and democratic education \\ in the context of deliberation and political agonism
}

A educação democrática no contexto
da deliberação e o agonismo politico

Fecha de entrega: 15 de septiembre 2015

Fecha de evaluación: 27 de octubre de 2015

Fecha de aprobación: 10 de noviembre de 2015

Sergio Luis Caro Arroyo*

\section{Resumen}

El propósito central de este artículo es realizar una exploración crítica de la idea de educación democrática. La tesis que se defiende es que existe una relación de complementariedad entre los modelos deliberativo y agonista de la democracia, defendidos por Amy Gutmann y Chantal Mouffe, que permite una comprensión de la educación que satisface las exigencias morales de una concepción democrática de ciudadanía. El

El presente texto se realiza en el marco del apoyo para la formación pos gradual a docentes del distrito de la Bogotá Humana, periodo 2012-2015, gestionado por la Secretaría de Educación del Distrito, a través de la Subsecretaría de Calidad y Pertinencia y la Dirección de Formación de Docentes e Innovaciones Pedagógicas.

- Candidato a Magíster en Filosofía de la Universidad del Rosario. Especialista en Filosofía del Derecho y Teoria Jurídica, Universidad Libre, Bogotá. Filósofo, Universidad del Atlántico. Docente de la SED Bogotá, IED Floridablanca, Colombia. Correo electrónico: asnofilosofo@gmail.com 
texto inicia con un planteamiento acerca de la relación entre política y educación; seguidamente, se exponen los enfoques agonal y deliberativo de la política en la interpretación de la democracia, para finalmente identificar los puntos de intersección de ambos modelos y proponer algunas líneas de reflexión en torno a la comprensión de la ciudadanía y la praxis de la formación ciudadana

Palabras clave: participación, educación democrática, deliberación, agonística, consenso.

\section{Abstract}

The core purpose of this article is to make a critical exploration of the idea of democratic education. The thesis of the author is that there is a complementary relationship between deliberative and agonist models of democracy, defended by Amy Gutmann and Chantal Mouffe, which allows an understanding of education that, meets the moral demands of a democratic conception of citizenship. The text begins with an approach to the relationship between politics and education; then, there is a presentation of the agonal and deliberative perspectives of politics in the interpretation of democracy, to finally identify the points of intersection of both models and propose some lines of reflection on citizenship and its praxis.

Keywords: Involvement, democratic education, deliberation, agonism, consensus.

\section{Resumo}

O propósito central de este artigo é realizar uma exploração crítica da ideia de educação democrática. A tese que se defende é que existe uma relação de complementariedade entre o modelo deliberativo e agonista da democracia, defendidos por Amy Gutmann e Chantal Mouffe, que permitem uma compreensão da educação que satisfaz as exigências morais de uma concepção democrática de cidadania. O texto inicia com uma exposição a respeito da relação entre politica e educação; após, se expõem os enfoques agonal e deliberativo da política na interpretação 
democracia, para finalmente identificar os pontos de intersecção de ambos modelos e propor algumas linhas de reflexão sobre a compressão da cidadania e a práxis da formação cidadã.

Palavras-chave: Participação, educação democrática, deliberação, agonística, consenso.

\section{Introducción}

La argumentación que se propone busca debatir los planteamientos que Amy Gutmann elabora en torno a la idea de educación democrática, esto, mediante el análisis de la crítica de la política agonística que Chantal Mouffe dirige en contra de la política deliberativa; si bien es cierto que el punto nodal de la crítica de Mouffe se centra directamente en la idea de consenso (esencial en la deliberación), en cualquier caso, ella sugiere una comprensión de lo político no reducible al procedimiento deliberativo, del cual, sin embargo, no prescinde de manera definitiva. Así, permite una lectura de la democracia en la que el agonismo y la deliberación son complementarios. La intersección de la política agonística y la deliberativa deviene en una concepción de la democracia en la que se articulan las ideas de procedimiento racional y consenso, sin que se afecten la contingencia y la apertura permanente de lo político, que se siguen del conflicto y la confrontación pluralista de centros de poder que aspiran a la hegemonía política. Este primer acercamiento tiene como propósito matizar el sentido de lo democrático en la idea de una educación democrática, por lo cual se defiende que la actitud política de un ciudadano democrático no radica en su disposición para integrarse sin más en un determinado sistema de instituciones y procedimientos sociales, sino que consiste en participar en ese sistema bajo la premisa de la contingencia del mismo, porque es solo tal disquisición la que daría lugar a acciones críticas tendientes a transformarlo.

\section{Política y educación}

La educación puede ser comprendida como una forma de acción política, dado que ella es un proceso que difícilmente se podría desligar del conjunto de las acciones sociales que tienen incidencia en la construcción de la ciudadanía en una comunidad política. Por otra parte, el ejercicio político que se realiza en una sociedad puede ser 
considerado como una acción educativa, puesto que interviene de manera sustancial en la construcción de la sociedad y, por ende, en la formación de los aspectos económicos y culturales que dan concreción y significado a la educación; en otras palabras, la acción educativa afecta la política, porque de ella depende en gran medida la formación ciudadana que define el compromiso y la conciencia de pertenencia a la colectividad política (Touraine, 2000).

La reflexión sobre los fines de la educación en su conexión con lo político pasa por cuestiones tan delicadas como las relativas al tipo de autoridad que debe mediar la relación educativa entre niños y adultos, en lo que respecta al valor de la tradición y al derecho de los niños, en virtud de la novedad que ellos representan para el mundo, de poder participar en la construcción de su futuro ${ }^{1}$ (Arendt, 1996), y al efecto de esto en la capacidad de los niños y jóvenes de juzgar y autodeterminarse moralmente (Adorno, 1993). Igualmente, cabe considerar el tema del fortalecimiento de la conciencia ciudadana, para que sea posible el compromiso moral con relación a un proyecto de sociedad pluralista (Touraine, 2000).

En la relación entre educación y política, autores como John Dewey (2004, 2011), Amy Gutmann (2001) y Guillermo Hoyos (2008, 2013a, 2013b), entre otros, privilegian una política de corte democrático, porque se entiende que ésta logra articular las demandas de libertad y autonomía de la persona en el contexto de su dimensión moral, con los compromisos que exige el ejercicio de la autoridad política de un orden social ${ }^{2}$. Con este propósito, el sistema de gobierno democrático se caracteriza esencialmente por tener una organización que busca beneficiar a sus gobernados, al

1 En su ensayo La crisis en la educación, Arendt indica el vínculo existente entre educación y política, como una relación en la que el ejercicio de una se manifiesta como una acción de la otra, de manera reciproca. En dicha conexión, la autoridad educativa se distingue de la autoridad política, porque ella se debe orientar a que los niños y jóvenes conozcan el mundo (entendido como el espacio y las tradiciones compartidas con los otros), para que se mantenga la continuidad con la vida adulta; sin que esto afecte la novedad que ellos representan para las posibilidades de transformación del mundo, es decir, para la construcción de un futuro. En este sentido, la esfera educativa debe realizarse de manera autónoma en relación con la esfera política, dado que esta última exige la pertenencia completa al mundo. Con esto, la educación se renueva siempre con la llegada de nuevos seres humanos, por lo que debe conservar la novedad de los nuevos humanos, debe enseñar sobre el mundo, pero no una forma exclusiva de vivir en el mundo o de ser del mundo (cf. Arendt, 1996, pp. 185-208).

2 Lo que aqui se busca expresar con la idea de "la articulación de las demandas de la libertad con la autoridad política" es que uno de los sentidos posibles de la educación democrática radicaría en servir de justificación para pensar el vínculo de la autoridad política y la persona en términos de obligación moral. 
mismo tiempo que garantiza que sean precisamente los gobernados los que decidan sobre qué es aquello que los beneficia (Lafont, 2011).

Bajo esta mirada, el proyecto de una educación democrática tendría por condiciones proteger la capacidad de autodeterminación moral de los individuos, y con ello la libertad (y el pluralismo que se genera del ejercicio de la misma), así como promover una ciudadanía basada en la cooperación social reflexiva ${ }^{3}$ (Honneth, 1999), el razonamiento público ${ }^{4}$ (Sen, 2010); y su compromiso con la distribución de la autoridad y los procedimientos decisorios característicos del autogobierno democrático (Bobbio, 1986), debidos a su participación en el ejercicio colectivo de la soberanía. Estas condiciones conllevan una serie de consecuencias que afectarían la comprensión del rol de los diferentes agentes educativos, en lo relativo a los criterios que utilizan para orientar sus acciones, así como en las categorías que están en la base de la manera como ellos comprenden el proceso educativo en el contexto de la sociedad democrática. Por lo anterior, el presente escrito se constituye como un acercamiento filosófico que busca discutir y avanzar en la comprensión de la normatividad de la idea de educación democrática.

Uno de los problemas centrales en torno a lo que significa una educación democrática es el de entender el sentido que lo político puede imprimir en la definición de lo democrático en el contexto educativo, dado el amplio espectro de interpretaciones sobre lo político y la democracia que participan del debate filosófico-político contemporáneo ${ }^{5}$. Esta dificultad exige delimitar el significado de "educación democrática" a partir de la identificación de una concepción de lo político que satisfaga las condiciones de la democracia mencionadas arriba, al mismo tiempo que las exigidas por las necesidades formativas propias de la educación. Con respecto a esto, la discusión se desarrolla entre varias posturas ${ }^{6}$, en las cuales se pueden reconocer dos extremos: aquellas posturas libertarias, que no ven que la educación ciudadana puede desempeñar función alguna y el otro extremo, conservador, que considera que la formación

3 La interpretación de la democracia como forma reflexiva de cooperación social obedece a la interpretación propuesta por Axel Honneth de las ideas politicas de John Dewey (Honneth, 1999).

4 Sen retoma aqui el debate Rawls-Habermas para señalar que, a pesar de las diferencias, ambos coinciden, como muestra del reconocimiento general, en que la comprensión de la democracia recoge entre sus cuestiones centrales la participación política, el diálogo, y la interacción pública.

5 Ver Gargarella (1999), Habermas (2010), Cuervo, Hernández y Ugarriza (2012), y Mejía (2004 y 2010).

6 Ver Gutmann (2001, pp. 37-96). 
de ciudadanía está centrada en la defensa de una nación. En medio de estas se encuentran concepciones de la educación que están centradas en la formación de una ciudadanía más bien crítica, y dentro de estas los más reconocidos son el enfoque deliberativo y el agonístico.

Por lo anterior, la discusión se limita aquí al contexto del debate de los enfoques deliberativo ${ }^{7}$ y agonístico de la política democrática, en las versiones de Amy Gutmann y Chantal Mouffe, respectivamente. Frente a esto, se asume el argumento de Isaiah Berlín (2014), según el cual "cuando hay acuerdo sobre los fines, los únicos problemas que restan son referidos a los medios, y estos problemas no son políticos sino técnicos" (p. 55). La política agonística y la deliberativa están de acuerdo en la comprensión de la ciudadanía como un ejercicio que incluye la crítica como forma de agencia constitutiva de lo social; además, en ambas perspectivas se desarrollan con igual importancia conceptos como participación, pluralismo o libertad. No obstante, existe un desacuerdo aparentemente insuperable, a saber, en el entendimiento de lo político como conflicto y confrontación, para el agonismo, y como deliberación racional y consenso, para el caso de la política deliberativa ${ }^{8}$. Así, una de las cuestiones que se tratan en este trabajo es la de las consecuencias morales y políticas (prácticas) que tiene para la comprensión de la educación democrática la afirmación radical de la dicotomía insalvable entre política deliberativa y agonística?

La discusión entre los modelos deliberativo y agonista permite evidenciar sentidos distintos (y aparentemente contrapuestos) acerca de la dimensión política de la democracia y de aspectos de la misma relativos a la comprensión de lo propiamente político del pluralismo, la participación, la ciudadanía y el consenso; lo cual influye en lo que

7 En el contexto de la democracia deliberativa, se presenta una serie de matices que se caracterizan en las propuestas de A. Gutmann (2001, 2004), David Estlund (2003, 2011a, 2011b) y Jürgen Habermas $(2010,1999)$. La diversidad de enfoques sobre lo político y la democracia producen igualmente una variedad de concepciones sobre el tipo de ciudadanía al que debe orientarse la educación, las que a su vez permiten identificar diferentes concepciones de la educación democrática. En este trabajo no entramos en ese debate.

8 Según Oliver Marchart (2009), para comprender este tipo de desacuerdo sobre lo político, vale la pena estudiar la diferencia entre H. Arendt y C. Schmitt: "los arendtianos ven en lo político un espacio de libertad y deliberación públicas, los schmittianos lo consideran un espacio de poder, conflicto y antagonismo" (p. 59).

9 El problema de fondo que se desarrolla en el debate entre deliberación y agonística, se expresa en la cuestión acerca de la contraposición entre una naturaleza conflictual o consensual de la política. Ver Grueso (2008) y Franzé (2014). 
podamos entender por educación democrática. Ante este panorama, el presente texto analiza tales aspectos, con el propósito de precisar la real magnitud de la sugerida dicotomía entre la agonística y la deliberación de los modelos de la democracia.

Por lo anterior, el presente trabajo propone, mediante el análisis de las ideas de pluralismo, participación, ciudadanía, autonomía y consenso, en el contexto del debate entre política deliberativa y agonística de la democracia, una comprensión de la educación democrática que integra los requerimientos de ambos modelos, en el sentido de que se precisa que la idea de política deliberativa defendida por Gutmann, así como la crítica de Mouffe, aportan reflexiones complementarias entre sí, las cuales, además de satisfacer las condiciones de autodeterminación (individual y colectiva), autogobierno, cooperación y participación y crítica, exigidas por los ideales moral y político de la democracia; sirven para trazar una serie de tareas ${ }^{10}$, sobre todo conceptuales, tendientes a configurar el perfil normativo de la idea de educación democrática. Estas tareas de análisis profundizan en la comprensión de la ciudadanía como participación (Kymlicka, 1996; Nussbaum, 1999; Habermas, 2010; Höffe, 2007), así como en la relación que ésta tendría con una lectura intersubjetivista del concepto de autonomía; las cuales devienen en la formulación de un principio de reconocimiento (Forst, 2005, 2012, 2014 y Honneth, 1997a, 1997b, 2014), esencial para comprender las diferentes fuentes de compromiso moral que se generan a partir de las relaciones cotidianas de las personas, y que pueden beneficiar la práctica educativa orientada a la formación de una ciudadanía democrática crítica y participativa.

\section{La educación democrática en la intersección de la agonística y la deliberación}

Una de las tareas iniciales para comprender lo que significa una educación democrática consiste en dilucidar lo que la democracia exige de sus ciudadanos (Clark, 1999). Esta tarea implica entender, primero, el sentido que lo democrático puede imprimir en lo educativo, cuestión que se torna compleja por la variedad de enfoques en disputa hoy sobre la democracia. Por esto, en esta sección nos limitaremos a discutir la aparente oposición entre la concepción deliberativa de la democracia y la concepción agonista. Una de las razones que conduce a la disyuntiva entre democracia

10 Las tareas que se mencionan se fundamentan en apartes relevantes de la presente reflexión; sin embargo, en este escrito solo se desarrolla la relación entre deliberación y agonismo. 
deliberativa y democracia agonista es la comprensión de lo político que cada enfoque adopta. En este sentido, Julián González (2014) señala en relación con este debate que "lo político ha de comprenderse bien desde una arista consensual o bien desde su costado más conflictivista" (p. 63); en ambos casos, una de las cuestiones de fondo se podría identificar con la diferencia del posicionamiento de cada perspectiva frente al pluralismo de las sociedades contemporáneas, y a la comprensión del papel de las diferencias en la dinámica de política democrática.

Bajo este entendido, la teoría deliberativa de la educación de Amy Gutmann defiende que la deliberación es la virtud democrática por excelencia y aquella necesaria para que exista una ciudadanía capaz de participar en la construcción consciente de la sociedad y en el ejercicio colectivo del poder político. Por su parte, Chantal Mouffe opina que la concepción de la democracia basada en las ideas de deliberación y consenso racional obedece a una comprensión errónea de lo político, dado que la idea de consenso conduce a la eliminación de las diferencias, mediante la construcción de una identidad que supone lograr el acuerdo; por lo cual, se expone al riesgo latente de la homogenización moral y a la negación del pluralismo, de allí que para esta autora lo político se refiera a lo antagónico, al conflicto que es constitutivo de las sociedades humanas (Mouffe, 2007, p. 16).

En este apartado se exponen algunos elementos de cada enfoque, con el propósito de hacer visibles los puntos de convergencia en lo relativo a aspectos como el pluralismo, el consenso, la participación y la ciudadanía.

\section{Enfoque agonístico de la democracia}

El modelo agonístico o radical de la democracia se presenta como una crítica al modelo deliberativo ${ }^{11}$. En líneas generales podemos identificar al menos dos críticas fuertes a este último paradigma: primero, que la idea de la política como consenso racional, que caracteriza a la democracia deliberativa, es incapaz de aprehender la dinámica política de la democracia moderna (Mouffe, 2012b), y segundo, el modelo deliberativo

11 Mouffe (1999) señala que "sólo si se reconoce la inevitabilidad intrínseca del antagonismo se puede captar la amplitud, de la tarea a la cual debe consagrarse toda política democrática. Esta tarea, contrariamente al paradigma de 'democracia deliberativa' que, de Rawls a Habermas, se intenta imponer como el único posible de abordar la naturaleza de la democracia moderna, no consiste en establecer las condiciones de un consenso racional, sino en desactivar el antagonismo potencial que existe en las relaciones sociales" (p. 13). Este pasaje capta un aspecto esencial de la teoría agonista de Mouffe, a saber, proponer una concepción de lo político contraria al modelo hegemónico, representado por la política deliberativa. 
según Mouffe es "conceptualmente erróneo [...] [e] implica riegos políticos" (Mouffe, 2012b. p. 10). La razón de lo anterior es que, al parecer, desde el punto de vista de Ernesto Laclau y especialmente de Chantal Mouffe, el modelo deliberativo erradica el conflicto y el antagonismo de la democracia (Mouffe, 2012b. pp. 61-64; 2007, pp. 36).

Podríamos identificar el enfoque de la democracia radical como un intento por redescribir el marxismo como teoría de la sociedad y de la política. Chantal Mouffe y Ernesto Laclau (2010) desarrollan una crítica a la idea del marxismo clásico de corte leninista que, embebido en un ideal racionalista, entiende que la historia, la sociedad y el sujeto son realidades homogenizables, determinables mediante la apropiación intelectual que supone el presupuesto epistemológico que las considera como realidades cuantificables, es decir, que ellas son de alguna manera, reducibles o articulables en una totalidad o unidad la cual se expresa en la tradición marxista bajo el concepto de "hegemonía" (Laclau y Mouffe, 2010). Para Mouffe y Laclau la totalidad o la identidad que el concepto de hegemonía busca fijar o articular opera conforme a una lógica que presupone la estabilidad de las realidades referidas, eliminando así la contingencia de lo político mediante la afirmación de la necesidad histórica del proyecto socialista. Es decir, el concepto de hegemonía articula los fragmentos pertenecientes a la totalidad ya dada de la sociedad y el sujeto con la necesidad histórica del proyecto socialista (Laclau y Mouffe, 2010); en este sentido, el concepto de hegemonía en el marxismo ortodoxo lo que hace es establecer una identidad esencial de lo político.

Frente a lo anterior, la reflexión de Mouffe y Laclau consiste en comprender la articulación de la hegemonía como práctica discursiva, en la cual la identidad de los elementos que se estructuran no subyace a la práctica misma, sino que emerge de esta, de las relaciones que la práctica discursiva produce, en la medida que el discurso fija parcialmente un momento de la totalidad posible; por lo cual, el sentido de lo que se llame objetivo no puede ser comprendido al margen de las condiciones discursivas de las que surge (Laclau y Mouffe, 2010). Esta interpretación se opone a la idea de que la sociedad, la historia y el sujeto puedan ser concebidos como realidades homogéneas $\mathrm{u}$ homogenizables, $\mathrm{y}$ da apertura a categorizaciones que funcionan como alternativa a las posibilidades de valor binarias contenidas en la lógica monotónica:

El carácter incompleto de toda totalidad lleva necesariamente a abandonar como terreno de análisis el supuesto de "la sociedad" como totalidad saturada y autodefinida. La sociedad no es un objeto legítimo del discurso. No hay principio subyacente único que fije -y así constituya- al conjunto del campo 
de las diferencias. La tensión irresoluble interioridad/exterioridad es la condición de toda práctica social: la necesidad solo existe como limitación parcial del campo de la contingencia. Es en el terreno de esta imposibilidad tanto de la interioridad como de la exterioridad totales, que lo social se constituye. Pero el hecho mismo de que la reducción de lo social a la interioridad de un sistema fijo de diferencias es imposible, implica que también lo es la pura exterioridad, ya que las identidades, para ser totalmente externas las unas respecto a las otras, requerirían ser totalmente internas respecto a sí mismas: es decir, tener una identidad plenamente constituida que no es subvertida por ningún exterior. Pero esto es precisamente lo que acabamos de rechazar. Este campo de identidades que nunca logran ser plenamente fijadas es el campo de la sobredeterminación (Laclau y Mouffe, 2010, p. 151).

En este pasaje los autores plantean cierta paradoja en la articulación hegemónica del poder, al hacer visible la imposibilidad de fijar definitivamente en la teoría las identidades de los elementos (sujeto, historia, sociedad) que se involucran en la política. La imposibilidad se manifiesta en que el discurso que demarca la objetividad posible nunca puede subsumir lo social totalmente, pero tal parcialidad no se explica porque algo como la esencia o el significado de lo social sea inaprehensible, sino precisamente porque hay un exceso de significados, una sobredeterminación de lo social que hace imposible la identificación absoluta al mismo tiempo que la no identificación absoluta (Laclau y Mouffe, 2010). En consecuencia, la fijación definitiva de las identidades resulta irrealizable, precisamente porque existe en el discurso la necesidad de fijarlas. Esta idea permite ir configurando un perfil de lo que se podría comprender como educación democrática: si se asume el carácter contingente de toda identidad, por razón del reconocimiento de su naturaleza discursiva, entonces, propósitos educativos como la formación ciudadana o el desarrollo moral no se podrían realizar como prácticas de adoctrinación orientadas al fomento de virtudes cívicas asociadas a la defensa de una nación, o al perfeccionamiento ético conforme a un ideal particular de bien. Por el contrario, dicha propuesta exige más bien que los objetivos educativos sean lo suficientemente abiertos y flexibles como para no convertirse en formas de exclusión o discriminación.

La imposibilidad de determinar lo social no supone que exista una exterioridad ${ }^{12}$ que así lo delimite. Para Mouffe y Laclau, la antinomia entre la contingencia de lo social

12 Con respecto al concepto de exterioridad o exterior constitutivo, Mouffe (1999) señala: "Esta noción [...] indica que toda identidad se construye a través de parejas de diferencia jerarquizadas: por ejemplo, 
y la necesidad discursiva que busca fundar lo social no se explica en relación con una instancia distinta, ni mediante la oposición real o la contradicción (Laclau y Mouffe, 2010), sino gracias a la experiencia del antagonismo, entendida como

la presencia del otro me impide ser totalmente yo mismo [...]. En la medida que hay antagonismo yo no puedo ser una presencia plena para mí mismo. Pero tampoco lo es la fuerza que me antagoniza: su ser objetivo es un símbolo de mi no ser [...] (Laclau y Mouffe, 2010, p. 168).

En este sentido, el antagonismo expresa "la imposibilidad de constituir una forma de objetividad social que no se funde en una exclusión originaria" (Mouffe, 1999, p. 12), es decir, el antagonismo no es producto de la institucionalización parcial de lo social que realiza el discurso, por el contrario, muestra el limite o la imposibilidad de dicha institucionalización. Sin embargo, lo antagónico aquí tampoco se refiere a alguna condición objetiva que determine la oposición de quienes antagonizan, porque esto supondría que el antagonismo es una construcción ya dada en el sistema discursivo, por lo cual podríamos afirmar que el antagonismo se refiere más a la situación en la cual no es posible que el discurso subsuma completamente lo social, a la vez que no es posible lo social sin algún tipo de discursividad que lo funde.

En este sentido, la hegemonía, como forma de articulación de lo político, no se comprende como una práctica que opera sobre un orden natural o trascendental de lo social, sino como un conjunto de acciones que crean o configuran lo social, de manera que la posibilidad de transformación se mantiene siempre latente. En este sentido, la comprensión política de las prácticas educativas en el contexto de una democracia tendría que privilegiar que las acciones pedagógicas que se realicen se orienten a generar experiencias de aprendizaje que promuevan la participación y

entre materia y forma, entre esencia y accidente, entre negro y blanco, entre hombre y mujer. La idea de 'exterior constitutivo' ocupa un lugar decisivo en mi argumento, pues, al indicar que la condición de existencia de toda identidad es la afirmación de una diferencia, la determinación de otro que le servirá de exterior, permite comprender la permanencia del antagonismo y sus condiciones de emergencia" (p. 15). Así, el contexto de exterioridad hace referencia a la relación de dependencia que existe entre un discurso que busca fundar una identidad y otros discursos, lo cual hace visible el carácter contingente de toda identidad. En este sentido, señalan Laclau y Mouffe (2010) "Con este "exterior" no estamos reintroduciendo la categoria de lo "extradiscursivo". El exterior está constituido por otros discursos. Es la naturaleza discursiva de este exterior la que crea las condiciones de vulnerabilidad de todo discurso, ya que nada lo protege finalmente de la deformación y desestabilización de su sistema de diferencias por parte de otras articulaciones discursivas que actúan desde fuera de él". (p. 150) 
cooperación de los estudiantes, en el entendido de que son precisamente este tipo de acciones las que están en la base del ejercicio de una ciudadanía comprometida con la construcción de una cultura cada vez más democrática.

El modelo agonista comprende que la idea de consenso, que expresa la pretensión del modelo deliberativo de aportar un procedimiento por medio del cual sea posible "superar el conflicto entre los derechos individuales y las libertades, por un lado, y las demandas de igualdad y participación popular por otro" (Mouffe, 2012b, p. 25), funciona como un mecanismo que contiene una forma hegemónica para la estabilización del conflicto. El consenso, para estos autores, tiene como efecto la desaparición de formas legítimas de resistencia en contra de las relaciones de poder dominante (Mouffe, 2012b); además, elimina la posibilidad de relaciones políticas genuinas, en el sentido de que, para Mouffe, dichas relaciones se constituyen sobre la base de la oposición amigo/enemigo propuesta por Carl Schmitt, según la cual, la identificación mutua de los integrantes de un grupo con respecto a una forma de acción colectiva, constituye la construcción de un "nosotros", el cual se expresa como una forma de identidad política, que es solo posible gracias al reconocimiento de su opuesto, un "ellos", que se refiere a las agrupaciones que se producen en torno a puntos de vista sobre la acción colectiva diferentes al nuestro, de manera que la posibilidad del "nosotros" tiene por condición la diferencia con respecto a un "ellos". En este orden de ideas, cuando se piensa la política como consenso, como el acuerdo de todos con respecto a un único punto de vista acerca de la acción colectiva, entonces, se erradica la posibilidad del "ellos” y, por tanto, la posibilidad misma de la política ${ }^{13}$; de allí que Mouffe (2104) considere que la cuestión esencial de la democracia

\section{[...] no reside en cómo llegar a un consenso logrado sin exclusión, ya que esto exigiría la construcción de un "nosotros" que no tendría su correspondiente "ellos". Esto es imposible, pues la condición misma de constitución de un "no- sotros" es la demarcación de un "ellos". La cuestión central es entonces cómo establecer esta distinción nosotros/ellos, que es constitutiva de la política,}

13 Para Mouffe (1999): "La vida politica nunca podrá prescindir del antagonismo, pues atañe a la acción pública y a la formación de identidades colectivas. Tiende a constituir un 'nosotros' en un contexto de diversidad y de conflicto. Ahora bien, [...] para construir un 'nosotros' es menester distinguirlo de un 'ellos'. Por eso la cuestión decisiva de una politica democrática no reside en llegar a un consenso sin exclusión -lo que nos devolvería a la creación de un 'nosotros' que no tuviera un 'ellos' como correlato-, sino en llegar a establecer la discriminación nosotros/ellos de tal modo que resulte compatible con el pluralismo" (p. 16). 
de manera tal que sea compatible con el reconocimiento del pluralismo. El conflicto en las sociedades democráticas liberales no puede -ni debería- ser erradicado, ya que la especificidad de la democracia pluralista es precisamente el reconocimiento y legitimación del conflicto (pp. 25-26).

La sociedad se presenta, entonces, como un entramado de relaciones de poder que no pueden ser erradicadas, por lo que el proyecto de la democracia radical y plural de Mouffe es consciente que de lo que se trata es de "transformarlas, renunciando al mismo tiempo a la ilusión de que podríamos liberarnos completamente del poder" (2012b, p. 39). En una sociedad comprendida de este modo, el agente político debe reconocer que sus pretensiones e intereses son particulares y limitados, de manera que no es posible que en la sociedad democrática un actor social tenga el derecho de atribuirse la representación de la totalidad de los actores (Mouffe, 2012b). Para Mouffe no hay algo así como un punto de vista político neutral o una condición imparcial que suponga de antemano una ventaja teórica o práctica en la dimensión antagónica de la sociedad (2012b).

Ahora bien, si éste es el tipo de sociedad y comunidad política que se concibe desde el modelo agonista de la democracia, entonces, ¿ cuál es el tipo de ciudadano que en ella se define? En la concepción de comunidad política de la agonística de Mouffe, se defiende la imposibilidad de formular la existencia de una idea de bien común que vincule de manera incondicional a todos los individuos que pertenecen a ella (Mouffe, 2014). Sin embargo, la misma idea de comunidad política exige que exista un vínculo entre sus integrantes, el cual se expresa, según Mouffe, de la siguiente manera:

Lo que compartimos y lo que nos hace ciudadanos en un régimen democrático liberal no es una idea sustantiva del bien sino un conjunto de principios políticos específicos de dicha tradición: los principios de libertad e igualdad para todos. [...] Ser ciudadano es reconocer la autoridad de aquellos principios y las reglas en los cuales se encarnan, basar sobre ellos nuestro juicio político y nuestras acciones. Estar asociados en términos de los principios liberales, ese es el sentido de la ciudadanía que quiero exponer (2012a, pp. 290-291).

La definición de ciudadanía de Mouffe parte de la distinción formulada por Michael Oakeshott entre universitas y societas (Mouffe, 2012a). En el caso de la universitas, la comunidad o asociación política se entiende como aquella en la que el vínculo social 
se justifica por la consecución de un fin específico asociado a un ideal de bien; en cambio, para el caso de la societas, la asociación se articula en relación con un conjunto de reglas, las cuales expresan el interés común de los asociados en definir una serie de condiciones morales que permitan orientar la acción en el contexto social. Dichas reglas posibilitan la creación de una identidad política, que a su vez permite la interacción entre grupos con distintos ideales de bien. El propósito de tales reglas no consiste servir de instrumento para promover los intereses particulares de un grupo específico, sino en que se reconozcan y promocionen todos los intereses particulares de todos los grupos que constituyen la sociedad democrática. En este contexto, la dimensión antagónica exige además el reconocimiento de que todo posible acuerdo en relación con las reglas admitidas es siempre la expresión de un poder hegemónico, que solo representa una alternativa posible y provisional del orden social y nunca la totalidad o expresión definitiva del mismo.

En este sentido, la ciudadanía en la democracia radical se entiende como una forma posible de identidad política, que se caracteriza porque permite la interacción entre los diferentes fines definidos por las ideas de bien de los diferentes grupos, sin que eso signifique no ser conscientes de que el reconocimiento de dichas reglas supone ya una forma de sumisión a un poder hegemónico que, sin embargo, se comprende como constituido y por esto, como transformable o sustituible, gracias, precisamente, a que la ciudadanía es su principio constitutivo (Mouffe, 2012a).

En resumen, en este aparte se ha mostrado que el modelo agonista interpreta la política como un espacio de conflicto, en donde el reconocimiento acerca de la imposibilidad de eliminar el desacuerdo y la diferencia se configura como la posibilidad misma de la democracia, en el sentido de que explican que todo orden social es una construcción, cuya hegemonía es susceptible de ser transformada mediante la acción (participación) de quienes la constituyen.

\section{Enfoque deliberativo de la democracia de Amy Gutmann}

Para Gutmann la deliberación expresa un procedimiento racional de decisión ${ }^{14}$, que hace manifiesto el poder comunicativo en las comunidades democráticas. Entre las

14 Para ampliar la información sobre las diferentes concepciones de la deliberación, ver Elster (2001) y Cuervo, Hernández y Ugarriza (2012). 
características de la deliberación, Gutmann identifica el reconocimiento del disenso como condición de posibilidad, teniendo en cuenta que la dinámica misma de la deliberación exige la confrontación y, por ende, el desacuerdo como punto de partida permanente; además, para ella el modelo deliberativo no supone un enfoque imparcial o neutral con respecto a las ideas de bien, por el contrario, cuenta con una base moral:

Virtualmente todos los demócratas deliberativos pueden estar de acuerdo en que el objetivo primario de la deliberación es justificar las decisiones y las leyes que los ciudadanos y sus representantes se imponen los unos a los otros. En este sentido, los demócratas deliberativos están de acuerdo en que la deliberación apunta por lo menos a una concepción débil del bien común (Gutmann y Thompson, 2004. pp. 35-36) ${ }^{15}$.

Desde este punto de vista, encontramos que la base moral mínima de la deliberación, que busca ser un principio de economía para el desacuerdo moral ${ }^{16}$, consiste en la exigencia equitativa de razones, en la reciprocidad sobre la crítica y la necesidad de justificación pública, la flexibilidad con respecto a otros métodos de decisión y la comprensión de las justificaciones y de los acuerdos como instancias abiertas, no definitivas, sobre las cuales es posible continuar la discusión. En este sentido, el demócrata deliberativo no cree que sea posible lograr acuerdos totalizantes e incondicionales, sino que apuesta por la práctica de un principio del desacuerdo moral, que permita la identificación de terrenos comunes para la cooperación más que el consenso absoluto (Gutmann y Thompson, 2004). Gutmann concibe la comunidad democrática como una construcción procedimentalmente articulada, gracias al ejercicio de la deliberación, por esta razón, la ciudadanía se entiende principalmente

15 En adelante, las citas de este texto son traducciones propias.

16 Amy Gutmann y Dennis Thompson entienden que "Una implicación importante de esta caracteristica dinámica de la democracia deliberativa es que el debate continuo requerido debería cumplir lo que llamamos el principio de economia de desacuerdo moral. Al dar razones para sus decisiones, los ciudadanos y sus representantes deberian tratar de encontrar justificaciones que minimicen sus diferencias con sus oponentes. Los demócratas deliberativos no esperan que la deliberación siempre o ni siquiera usualmente lleve a un acuerdo. Como los ciudadanos manejan el desacuerdo que es común en la vida política deberia ser por consiguiente una pregunta central en cualquier democracia. Practicar la economía del desacuerdo moral promueve el valor del respeto mutuo (el cual es central a la democracia deliberativa). Al economizar en sus desacuerdos, los ciudadanos y sus representantes pueden continuar trabajando juntos para hallar cosas en común, si no se puede en las políticas que produjeron el desacuerdo, entonces en otras políticas en las que tengan mayor posibilidad de llegar a un acuerdo" (p. 7). 
como el ejercicio de participación que realiza el agente social, bajo los principios de libertad e igualdad.

Estas líneas generales de la deliberación permiten a Gutmann configurar una idea de educación democrática que se caracteriza por la primacía de la educación política, que promueve las habilidades relacionadas con el conocimiento y la moral y que son necesarias para la participación política y la formación de un ciudadano capaz de deliberar y tomar decisiones teniendo en cuenta principios democráticos (Gutmann, 2001). Así, la educación democrática tiene por objetivo la formación de ciudadanos capaces de interesarse por los otros y de no ser pasivos frente a las decisiones políticas que acontecen en su entorno social (Gutmann, 2001). Esta visión muestra la dificultad de disociar la reflexión sobre la educación (sus procesos, fines y contenidos) de la reflexión sobre la democracia (Gutmann, 2001); la razón principal radica en la convicción histórica de que la democracia no solo es una opción entre varias de un sistema de gobierno, sino, además, porque ella cuenta con el potencial de lograr que los ciudadanos tengan la autonomía suficiente para construir un orden de vida colectivo mediante el ejercicio de la autoridad política, a la vez que se mantiene el respeto de sus libertades.

En este sentido, pensar la educación democrática resulta una tarea que exige trascender las preocupaciones puramente didácticas y pedagógicas, para tratar de articularlas a una teoría política democrática, al mismo tiempo que busca identificar y orientar las implicaciones educativas del ejercicio político. El propósito de esta tarea consiste en la configuración de una idea de la formación ciudadana que no quede expuesta al peligro del adoctrinamiento ${ }^{17}$, manteniendo el propósito educativo de la autonomía moral, así como las obligaciones políticas orientadas a facilitar la cooperación social.

17 Eamon Callan y Dylan Arena (2009) señalan "Cuando se hacen acusaciones de adoctrinamiento, la imputación de mal acto moral tiene que ver con una distorsión sistemática de cierto tipo en la presentación por parte del profesor de la materia -una distorsión que provoca, o que sensatamente se puede esperar que provoque, una distorsión correspondiente en la manera en que los estudiantes entienden la materia. Además, la distorsión no debe ser, por lo menos en los casos típicos, explicada por la pereza o indiferencia intelectual, que a menudo explica la enseñanza meramente inefectiva, sino por un esfuerzo exagerado o mal planeado de inculcar creencias particulares o valores" (p. 105). En este sentido, el adoctrinamiento se entiende como el aprovechamiento del rol docente o educativo para promover creencias o valores que de alguna manera agreden la libertad de los niños y, por tanto, su autonomía, dado que se modelan sus creencias sin tener en cuenta su derecho futuro a poder establecer preferencias. 
Frente a este problema, Amy Gutmann (2001) desarrolla una teoría política de la educación que se centra en reflexionar sobre cuál sería la educación más adecuada para la participación en la construcción colectiva y consciente de la sociedad; de este modo, una de sus tareas principales radica en definir quién o quiénes tienen el derecho de ejercer la autoridad educativa. Esto, porque en dicha acción se asegura el tipo o los tipos de carácter moral que habrán de fomentarse para que se garantice la participación en la definición colectiva de la sociedad, conforme a los llamados principios de no represión y no discriminación. Por un lado, el principio de no represión "previene que el Estado, y cualquier grupo de su interior, utilicen la educación para restringir la deliberación racional entre concepciones competitivas de buena vida y buena sociedad" (Gutmann, 2001, p. 65). Por su parte, el principio de no discriminación busca garantizar el derecho a la participación, en cuanto "impide que el Estado o grupos en su interior nieguen a alguien (en la educación dicha discriminación toma su forma en contra de minorías raciales, niñas, o grupos de niños desfavorecidos) un bien educativo en términos irrelevantes para la prosecución legítima de ese bien" (Gutmann, 2001, pp. 66-67). Tales principios son los que, en últimas, garantizarían la libertad y la igualdad. Por esta razón, la educación democrática exige un tipo de distribución de la autoridad educativa que proteja la libertad moral manifiesta en la capacidad de deliberar y el derecho a la autodeterminación individual y colectiva, lo cual es posible gracias al ejercicio de la participación.

El argumento de Amy Gutmann se sustenta en la idea de que la deliberación es la virtud democrática por excelencia (Gutmann, 2001), por lo que su concepción de lo democrático se comprende fundamentalmente como una forma de gobierno en la que se hace necesario que los ciudadanos y sus representantes justifiquen sus decisiones políticas mediante la dinámica de dar y responder razones (Gutmann y Thompson, 2004). Partiendo de lo anterior, lo político se refiere al conjunto de acciones orientadas a la búsqueda de acuerdos relativos a la organización de la sociedad. Dichas acciones no parten de la nada, o son neutrales con respecto a los valores que se cree deben promoverse; por el contrario, reconocen que la defensa de la libertad moral y la identidad grupal (Gutmann, 2008) son la base sustantiva de la democracia, a partir de la cual se orienta la búsqueda del consenso social. Ahora bien, este consenso no se entiende como una especie de instancia definitiva de la deliberación, en cambio, Gutmann defiende que la naturaleza de los compromisos sociales que está en la base de tales acuerdos consiste en ser perpetuamente vulnerables a las críticas que puedan esgrimirse desde diferentes lugares (Gutmann y Thompson, 2010). 
Finalmente, el enfoque propuesto por Gutmann define una base moral de la deliberación, la cual se refiere a la idea de que las personas no deberían ser tratadas como meros objetos de legislación, como sujetos pasivos destinados a ser gobernados, sino como agentes autónomos que participan en el gobierno de su propia sociedad, directamente o a través de sus representantes. En la democracia deliberativa una manera importante en la que estos agentes participan es presentando y respondiendo a razones, o exigiendo que sus representantes hagan lo mismo, con el objetivo de justificar las leyes bajo las cuales ellos deben vivir juntos (Gutmann y Thompson, 2010). Las razones son para producir una decisión justificable y para expresar el valor del respeto mutuo. En este sentido, el modelo deliberativo se presenta como una concepción de la política que no es neutral frente a unos ideales de lo bueno, aunque esto no implica establecer alguno que se imponga sobre los derechos de participación y autodeterminación individual y colectiva, lo cual no es agresivo para el reconocimiento del conflicto que está en la base del pluralismo.

\section{La educación democrática en la intersección de la deliberación y la agonística}

Una vez reconstruidos en líneas generales los dos modelos, en lo que sigue discutiremos los puntos de intersección y tensión entre estas dos teorías. Un primer punto de intersección de la política agonística y la política deliberativa se ubica en la idea de consenso: para ambas el consenso es una condición necesaria en la comprensión de la democracia, la diferencia radica en la gradación de la dimensión y protagonismo que ambas posiciones le conceden. Mouffe (2012a) no desconoce que los acuerdos y el consenso forman parte de la dinámica política, sin embargo, mantiene la prevención frente a ellos, al señalar que siempre refieren a algún tipo de exclusión, por lo que deben ser considerados como parciales y provisorios. En este punto encontramos una fuerte similitud con Gutmann, según la cual

La tercera característica de la democracia deliberativa es que su proceso apunta a producir una decisión que sea vinculante por un periodo de tiempo. En este respecto el proceso deliberativo no es como un show de televisión donde se discute o un seminario académico. Los participantes no discuten por discutir; ni siquiera discuten por la verdad (aunque la veracidad de sus argumentos es una virtud intencional porque es un objetivo necesario en la justificación de su decisión). Ellos quieren que su discusión influya una decisión que el gobierno 
tomará, o un proceso que afectará cómo se tomarán las futuras decisiones. En algún punto, la deliberación cesa temporalmente, y los líderes toman una decisión (Gutmann y Thompson, 2004, p. 5).

En esta cita, el consenso no es una situación definitiva o conclusiva en el proceso deliberativo, no obstante, la deliberación no se puede prolongar indefinidamente en el tiempo, cuando existe la exigencia práctica de tomar una decisión, de esto no se sigue que las justificaciones que se logren en determinado momento se conviertan en intemporales y constituyan el fin de la deliberación. Al contrario, la decisión y la ejecución de la misma motivan que el proceso deliberativo continúe, esta vez, como un ejercicio evaluativo frente a las justificaciones presentadas $\mathrm{y}$ frente al proceso mismo. Es decir, el consenso en la deliberación no conduce necesariamente al fin del conflicto, por el contrario, puede motivarlo en una dimensión diferente a la inicial ${ }^{18}$. Esta última idea remite a la tesis de Mouffe acerca del "consenso conflictual", según la cual:

\begin{abstract}
Aunque el consenso sin duda es necesario, debe estar acompañado por el disenso. Es preciso que exista consenso sobre las instituciones que son constitutivas de la democracia liberal y respecto de los valores ético-políticos que deberían inspirar la asociación política. Pero siempre va a existir desacuerdo en torno al significado de esos valores y al modo en el que deberían implementarse. Este consenso siempre será, por lo tanto, un "consenso conflictual" (Mouffe, 2014, p. 27).
\end{abstract}

Un segundo punto de intersección se expresa en el carácter ontológico o condicional para lo político, con el que cada enfoque concibe al conflicto (como expresión del pluralismo, para la comprensión de lo político). Para este punto resulta útil la distinción propuesta por Mouffe (2007) entre la política y lo político:

[...] considero "lo político" como la dimensión de antagonismo que considero constitutiva de las sociedades humanas, mientras entiendo a "la política" como el conjunto de prácticas e instituciones a partir de las cuales se crea un determinado orden, organizando la coexistencia humana en el contexto de la conflictividad derivada de lo político (p. 16).

18 Como caso paradigmático, Gutmann y Thompson (2004) analizan el proceso y los elementos de la decisión que llevaron a EE. UU a la guerra con Irak. 
Con esto, para Mouffe lo político de la democracia radica, siguiendo parcialmente a Carl Schmitt ${ }^{19}$, en el reconocimiento de la diferencia de los grupos políticos identitarios bajo la relación nosotros/ellos, que Schmitt comprende como la relación antagónica amigo/enemigo, pero que Mouffe reinterpreta como una relación agonista, en la que los oponentes se reconocen mutuamente como adversarios legítimos. Por esta razón, "la pregunta principal que ha de responder la política democrática no es la de cómo eliminar el poder sino la de cómo constituir formas de poder más compatibles con los valores democráticos" (Mouffe, 2012b, p. 112). En este orden de ideas, el "pluralismo agonístico" propuesto por Mouffe se entiende como el punto de vista que considera que la relación antagónica entre identidades políticas diferentes no supone que el "otro" político debe ser entendido necesariamente como un enemigo al que se debe eliminar, más bien se concibe como un adversario, que "es un enemigo, pero un enemigo legítimo, un enemigo con el que tenemos una base común porque compartimos una adhesión a los principios ético-políticos de la democracia liberal: la libertad y la igualdad” (Mouffe, 2012b, p. 115). Para Mouffe, la política, en cuanto se refiere a la institucionalización de prácticas de gobierno, tiene por objetivo la domesticación de lo político. Tal planteamiento pretende configurar una concepción radical del pluralismo, en la que se entiende, dada la contingencia del poder hegemónico constitutivo que funda todo orden social, que la participación de tales grupos políticos tiene la posibilidad real de transformar y cambiar la hegemonía vigente (Mouffe, 2007).

Una de las condiciones del enfoque deliberativo de Gutmann es el reconocimiento de que las sociedades democráticas modernas se caracterizan por presentar diferencias sustanciales de opinión entre sus ciudadanos, a partir de las cuales se organizan en una pluralidad de grupos con identidades sociales distintas (Gutmann, 2001). Tal condición es el motivo del desacuerdo que hace posible la deliberación; razón por la cual, "el pluralismo es un valor político importante en la medida que la diversidad

19 En su análisis de la obra de Schmitt, Mouffe resalta su crítica al modelo parlamentarista liberal de la democracia: "A juicio de Schmitt, el elemento representativo constituye el aspecto no democrático de la democracia parlamentaria en la medida en que se hace imposible la identidad entre gobierno y gobernados, inherente a la lógica de la democracia. [...]. En este sistema, la discusión pública, que es interrelación dialéctica de opiniones, ha sido reemplazada por la negociación partidista y el cálculo de interés; los partidos se han convertido en grupos de presión, 'que calculan sus intereses reciprocos y sus respectivas oportunidades de ocupar el poder, y en realidad llegan a acuerdos y coaliciones sobre esta base. [...] Esto se produjo de la siguiente manera [...] que toda una serie de preguntas dificiles relativas a la moral, la religión y la economia estuvieran confinadas a la esfera privada'". (Mouffe, 1999, p. 163) 
social enriquece nuestras vidas mediante la expansión de nuestro entendimiento de las diferentes formas de vida" (Gutmann, 2001, p. 52). De allí que Gutmann entienda que los desacuerdos razonables de las personas que participan en un proceso de deliberación deben ser respetados bajo el principio de la igualdad política (Gutmann, 2004) y también, porque el respeto mutuo, que puede entenderse como una forma de legitimación del adversario, es una condición necesaria para que se dé la deliberación (Gutmann y Thompson, 2010); incluso Gutmann entiende que los grupos identitarios son un efecto inherente de la libertad de asociarse que gozan los ciudadanos de una democracia (Gutmann, 2008). No obstante, al igual que Mouffe, Gutmann reconoce que el conflicto debe ser de alguna manera limitado o domesticado, lo que no significa eliminado.

Mediante el planteamiento de los principios de no represión y no discriminación, Gutmann $^{20}$ establece una restricción moral para los grupos identitarios que es análoga a la exigencia del respeto de la libertad y la igualdad defendido por Mouffe. En este punto, podemos afirmar que Mouffe estaría de acuerdo con Gutmann en que en una educación democrática "tratar cada opinión moral como igualmente válida anima en los niños el falso subjetivismo de 'yo tengo mi opinión y tú la tuya', ¿y quién ha de decir quién tiene la razón?” (Gutmann, 2001, pp. 78), dado que este tipo de relativización conduce a generar indiferencia frente a los valores que se promueven, lo cual anula el ejercicio crítico que supondría la afirmación de valores que promocionen, por ejemplo, la discriminación racial o de género ${ }^{21}$.

20 Para Gutmann no todos los desacuerdos deben permanecer sin resolver en una democracia, dado que pueden existir grupos que promuevan el racismo, la homofobia o cualquier otro tipo de discriminación, de alli que entienda que: "Aunque los pluralistas están de acuerdo en que la deliberación debería tratar de justificar la mayor cantidad de acuerdo posible, ellos también buscan maneras de vivir bien con esos desacuerdos que no pueden o no deberían ser eliminados en un momento dado. Esta es una diferencia profunda e irreconciliable entre demócratas que aceptan el pluralismo como parte de la condición humana y aquellos que lo ven como un problema politico serio que debe ser superado con la deliberación. Algunos desacuerdos - por ejemplo, una petición de excluir a los negros, judios, u homosexuales de varias asociaciones- le exigen a la democracia que confirme su compromiso con los principios de la no discriminación e igual oportunidad en su forma esencial. Pero otros desacuerdos no deberian ser resueltos. Llamamos a estos desacuerdos deliberativos: incluyen conflictos no entre ideas que son claramente correctas y claramente incorrectas, sino entre opiniones ninguna de las cuales puede ser razonablemente rechazada." (Gutmann y Thompson, 2004, p. 28).

21 Un ejemplo del punto de vista de Mouffe con respecto a la defensa de la libertad y la igualdad como valores democráticos, lo encontramos en su opinión acerca de las luchas feministas, para Mouffe (1999) "el feminismo es la lucha por la igualdad de las mujeres, [...] una lucha en contra de las múltiples formas en que la categoria 'mujer' se construye como subordinación" (p. 126). De esto no se sigue 
Finalmente, podríamos señalar un tercer punto de intersección de la agonística y la deliberación de Mouffe y Gutmann, a saber: ambos enfoques defienden una visión constructivista del orden social, es decir, ambos rechazan la idea de la política como administración ${ }^{22}$, según la cual, ella rige un orden externo o anterior, que subyace de manera inmodificable a su propio ejercicio. Así, Mouffe explica que todo orden social consiste en el ejercicio constitutivo de un poder hegemónico, el cual, gracias al antagonismo siempre latente en las sociedades democráticas, puede ser transformado y cambiado. Al respecto, Mouffe identifica al menos dos estrategias que operan en este tipo de transformación de la hegemonía imperante, las cuales son una expresión la democracia radical hoy: se trata de la "deserción de las instituciones"23 y el "involucramiento crítico con las instituciones" 24 . Por su parte, Gutmann remite a la idea de "reproducción social consciente", con la cual expresa la finalidad de la educación democrática y con ello, el objetivo de la deliberación racional en una democracia, a saber, que los ciudadanos participen en la elección de aquellos valores sobre los cuales se constituirán y transformarán las instituciones políticas; tal concepción pone en la base del orden social el derecho a la participación y a la autodeterminación moral y colectiva de los ciudadanos democráticos. En este orden de ideas, encontramos que para ambos enfoques la participación se comprende como un valor esencial de la ciudadanía, debido a que su ejercicio se concibe como la acción constituyente del orden social, y como el potencial político para transformarlo y conservarlo.

que exista solo una perspectiva válida del feminismo, aunque sí, que en sus diversas formas, es una lucha justificada por la igualdad.

22 Algunos teóricos de la política describen su comprensión sobre la base de la contraposición entre una interpretación de la política como administración y otra de la política como creación; según esto "en la concepción administrativa de la política, ésta aparece como siempre sujeta a elementos externos. Esto se da de dos maneras tradicionales: pensando la politica como un ámbito junto a otros de la vida social (Estado o sistema político) y/o como subordinada a fuentes externas inmodificables para la acción humana (la historia, la biología, el sentido del mundo, la naturaleza humana). [...] La concepción de la política como creación contingente radical supone abandonar la noción de lugar presente en la visión administrativa de la política como ámbito y de subordinación a otras instancias, para entrar en la intensidad y cristalización del sentido que permite la configuración misma de la comunidad y su orden". (Franzé, 2013, pp. 16-17)

23 "Este enfoque concibe a la política radical en términos de una deserción de las instituciones existentes, a fin de fomentar la auto-organización de la multitud". (Mouffe, 2014, p. 82)

24 Esta estrategia se refiere a "la rearticulación discursiva de los discursos y prácticas ya existentes. De esta manera nos permite concebir esta transición en términos de una intervención hegemónica" (Mouffe 2014, p. 82). 
En resumen, el análisis de los puntos de intersección entre el enfoque deliberativo y el agonista de la democracia no solo hace visible una coincidencia en sus fines o propósitos, sino que además permite una comprensión de la dimensión política de la educación democrática, según la cual, se pueden identificar al menos tres líneas para ir configurando un criterio para la comprensión de la ciudadanía y la praxis de la formación ciudadana, esto es:

I. Un ciudadano democrático entiende la necesidad de los acuerdos y el consenso como alternativa no violenta para resolver los conflictos, pero además es consciente de la imperfección de los procedimientos y del consenso mismo, por lo que no ve las reglas de juego vigente de la discusión y los posibles acuerdos como prácticas que agotan de manera definitiva las posibilidades políticas de la decisión.

II. Un ciudadano democrático es sensible frente a las diferencias relativas a las distintas concepciones del bien, sin embargo, no tolera que en nombre del pluralismo se promuevan concepciones de bien represivas o discriminatorias.

III. Un ciudadano democrático es consciente del poder y de la responsabilidad del ejercicio del poder que representa su derecho a la participación para la construcción y trasformación del orden social.

El propósito de este apartado no solo fue reconstruir el debate agonismo-deliberación para elaborar una interpretación complementaria de tales modelos, también se mostró una comprensión de lo político no reducible al procedimiento deliberativo, o más bien, que una política deliberativa no puede presentarse como un procedimiento que agota la dimensión de lo político. También se describió cómo la intersección de la política agonística y la deliberativa deviene en una concepción de la democracia en la que se articulan las ideas de procedimiento racional y consenso, sin que se afecte la contingencia y apertura permanente de lo político, que se siguen del conflicto y la confrontación pluralista de identidades colectivas que aspiran a la hegemonía política. Finalmente, se propuso una reflexión inicial del sentido de lo democrático en la idea de una educación democrática; por lo cual se planteó que la actitud política de un ciudadano democrático no radica en su disposición de integrarse sin más en un determinado sistema de instituciones y procedimientos sociales, sino que consiste en participar en ese sistema bajo la premisa de la contingencia del mismo, porque es solo tal concepto el que le permitiría acciones críticas tendientes a la transformación. 


\section{Referencias}

Adorno, T. (1993). Consignas. Buenos Aires: Amorrourtu.

Arendt, H. (1996). Entre el pasado y el futuro: Ocho ejercicios sobre la reflexión política. Barcelona: Península.

Berlín. I. (2014). Dos conceptos de libertad. El fin justifica los medios. Mi trayectoria intelectual. Madrid: Alianza Editorial.

Bobbio, N. (1986). El Futuro de la Democracia. México, D. F.: Fondo de Cultura Económica.

Callan, E. y Dylan, A. (2009). Indoctrination. En H. Siegel, The Oxford Handbook of Philosophy of education (pp. 104-121). New York: Oxford University Press.

Clark Power, F. (1999). La educación para la democracia. ¿Cómo ponerla en práctica? Perspectivas: revista trimestral de educación comparada, 29, No. 2, 236-243.

Cuervo, J., Hernández y Ugarriza, J. (2012). El giro deliberativo en la democracia: Teoría y evidencia empírica. Bogotá: Universidad Externado de Colombia.

Dewey, J. (2004). Democracia y Educación. Madrid: Morata.

Dewey, J. (2011). Selección de textos [Selección y traducción de Diego Antonio Pineda Rivera]. Medellín: Universidad de Antioquia.

Elster, J. (comp.). (2001). La democracia deliberativa. Barcelona: Gedisa.

Estlund, D. (2003). The Democracy/Contractualism Analogy. Philosophy \& Public Affairs, 31, No. 4, 387-412.

Estlund, D. (2011a). La autoridad democrática: Los fundamentos de las decisiones políticas legítimas. Buenos Aires: Siglo XXI Editores.

Estlund, D. (2011b). Reply to Copp, Gaus, Richardson, and Edmundson. Ethics, 121, No. 2, 354-389.

Forst, R. (2005). El derecho básico a la justificación: hacia una concepción constructivista de los derechos humanos. Estudios Políticos, No. 26, 27-59.

Forst, R. (2012). The Right of justification. New York: Columbia University Press. 
Forst, R. (2014). Justificación y crítica: Perspectivas de una teoría crítica de la política. Buenos Aires: Katz.

Franzé, J. (2014). La política ¿administración o creación? En Democracia: ¿Consenso o conflicto? Agonismo y teoría deliberativa en la política contemporánea (pp. 1541). Madrid: Catarata.

González, J. (2014). Habermas y Mouffe: La democracia entre consenso y conflicto. En J. Franzé (coord.). Democracia: ¿Consenso o conflicto? Agonismo y teoría deliberativa en la política contemporánea (pp. 63-90). Catarata: Madrid.

Grueso, D. (2008). La filosofía y la política en el pluralismo: La metafilosofía del último Rawls. Bogotá: Siglo del Hombre Editores.

Gargarella, R. (1999). Las teorías de la justicia después de Rawls. Un breve manual de filosofía política. Barcelona: Paidós.

Gutmann, A. y Dennis, T. (2004). Why Deliberative Democracy? New Jersey: Princeton University.

Gutmann, A. (2001). La educación democrática: una teoría política de la educación. Barcelona: Paidós.

Gutmann, A. (2004). Democracia deliberativa y regla de la mayoría: Una réplica a Waldron. En H. Hongju, Harold y S. Ronald. Democracia deliberativa y derechos humanos (pp. 269-278). Barcelona: Gedisa.

Gutmann, A. (2008). La identidad en democracia. Buenos Aires: Katz.

Habermas, J. (1999). Tres Modelos Normativos de Democracia. En La inclusión del otro: Estudios de Teoría Política (pp. 231-346). Barcelona: Paidós.

Habermas, J. (2010). Facticidad y validez: sobre el Derecho y el Estado Democrático de Derecho en términos de teoría del discurso. Madrid: Trotta.

Honneth, A. (1997a). Reconocimiento y obligación moral. Areté Revista de Filosofía, 9, No. 2, 235-252.

Honneth, A. (1997b). La lucha por el reconocimiento: Por una pragmática moral de los conflictos sociales. Barcelona: Crítica.

Honneth, A. (2014). El derecho de la libertad: Esbozo de una eticidad democrática. Buenos Aires: Katz. 
Honneth, A. (1999). La Democracia como Cooperación Reflexiva. John Dewey y la teoría de la Democracia del Presente. Estudios Políticos, No. 15, 81-106.

Hoyos, V. G. (2013a). Ensayos para una teoría discursiva de la educación. Bogotá: Civitas Magisterio.

Hoyos, V. G. (2013b). Filosofía de la educación: Apuntes de su último seminario. Bogotá: Siglo del Hombre Editores.

Hoyos, G. (2008). La comunicación: la competencia ciudadana. En G. Hoyos y A. Ruiz. Ciudadanías en formación (pp. 135-172). Bogotá: Civitas Magisterio.

Kymlicka, W. (1996). Ciudadanía multicultural. Barcelona: Paidós.

Laclau, E. y Mouffe, C. (2010 [1985]). Hegemonía y estrategia socialista: hacia una radicalización de la democracia. Ciudad de México: Fondo de Cultura Económica.

Lafont, C. (2011). ¿Es coherente el ideal de la democracia deliberativa? En L. García Jaramillo. La democracia deliberativa a debate (pp. 21-40). Medellín: Universidad Eafit.

Marchart, O. (2009). El pensamiento político posfundacional: la diferencia política en Nancy, Lefort; Badiou y Laclau. Buenos Aires: Fondo de Cultura Económica.

Mejía Quintana, O. (2004). El posestructuralismo en la filosofía política francesa contemporánea: Presupuestos, críticas y proyecciones. Bogotá: Universidad Nacional de Colombia.

Mejía Quintana, O. (2010). Modelos alternativos de democracia deliberativa. Una aproximación al estado del arte. Revista Co-herencia, 7, No. 12, 43-79.

Mouffe, C. (1999). El retorno de lo político: Comunidad, ciudadanía, pluralismo, democracia radical. Barcelona: Paidós

Mouffe, C. (2007). En torno a lo político. Ciudad de México: Fondo de Cultura Económica.

Mouffe, C. (2012a). Dimensiones de democracia radical. Buenos Aires: Prometeo.

Mouffe, C. (2012b). La paradoja democrática: El peligro del consenso en la política contemporánea. Barcelona: Gedisa. 
Mouffe, C. (2014). Agonística: Pensar el mundo políticamente. Buenos Aires: Fondo de Cultura Económica.

Nussbaum, M. (1999). Los límites del patriotismo. Barcelona: Paidós.

Sen, A. (2010). La idea de justicia. Bogotá: Taurus.

Touraine, A. (2000). ¿Qué es la democracia? México, D. F.: Fondo de Cultura Económica. 